\title{
Conforto ambiental de bezerros bubalinos (Bubalus bubalis Linnaeus, 1758) em sistemas silvipastoris na Amazônia Oriental
}

\author{
Raimundo José MORAES JÚNIOR ${ }^{1}$, Alexandre Rossetto GARCIA² ${ }^{2}$ Núbia de Fátima Alves dos SANTOS², \\ Benjamim de Souza NAHÚM ${ }^{4}$, José de Brito LOURENÇO JUNIOR ${ }^{5}$, Cláudio Vieira de ARAÚJO ${ }^{6}$, Norton \\ Amador da COSTA ${ }^{7}$
}

\begin{abstract}
RESUMO
Foi analisado o efeito de dois sistemas silvipastoris nos índices de conforto ambiental e alteraçóes nos parâmetros fisiológicos de bezerros bubalinos criados na Embrapa Amazônia Oriental, Belém-PA (clima Afi), no Período 1 (abril a setembro/2007) e Período 2 (outubro/2007 a março/2008). Foram inseridos onze bezerros no Sistema Silvipastoril 1 (SSP1), que apresentava sombreamento útil nas pastagens de 18 a 21\%, e oito no Sistema Silvipastoril 2 (SSP2), sem sombreamento, com lago para banho. Foram mensuradas as variáveis fisiológicas: temperatura retal (TR), frequência respiratória (FR), temperatura da pele (TP), e calculados o Índice de Temperatura e Umidade (ITU) e Índice de Conforto de Benezra (ICB), nos dois períodos experimentais, comparados pelo Teste Tukey $(\mathrm{P}<0,05)$. O ITU apresentou diferença estatística entre horários $(\mathrm{P}<0,05)$ e período do ano $(\mathrm{P}<0,05)$, e oscilou de $73,5 \pm 1,3$ até $82,2 \pm 0,8$. A TR apresentou diferença estatística entre horários e períodos do ano $(\mathrm{P}<0,05)$, com amplitude de $38,3 \pm 0,26$ a $39,3 \pm 0,38^{\circ} \mathrm{C}$. A FR apresentou diferença significativa entre horários $(\mathrm{P}<0,05)$, com amplitude de 32,2 $\pm 9,2$ a 56,5 $\pm 19,0$ mov $\mathrm{min}^{-1}$, consideradas acima dos níveis normais, enquanto a TP foi diferente estatisticamente entre períodos e horários $(\mathrm{P}<0,05)$ e variou de $23,6 \pm 8,3$ a $31,7 \pm 5,4^{\circ} \mathrm{C}$. Nos Períodos 1 e 2 e nos dois SSP's, os ICBs estiveram acima do valor ideal, variando de 2,46 $\pm 0,33$ a 3,31 $\pm 0,62$ (SSP1) e 2,42 $\pm 0,30$ a $3,45 \pm 0,66$ (SSP2).
\end{abstract}

PALAVRAS-CHAVE: ambiência, bem-estar animal, produção animal, sistema de criação.

\section{Environmental comfort of buffalo calves (Bubalus bubalis Linnaeus, 1758) on silvopastoral systems in the Eastern Amazon}

\begin{abstract}
This aim of the study was evaluating effects of two different silvopastoral systems on environmental comfort and changes in physiological parameters of buffalo calves bred in the Eastern Amazon. The experiment was conducted at Embrapa Amazônia Oriental, Belém-PA, (Afi climate type) in two periods of the year: Period 1 (April to Sep/2007) and Period 2 (Oct/2007 to March/2008). Eleven calves were included in the Silvopastoral System 1 (SSP1), with a useful shaded pasture area of 18 to 21\%; and eight calves were included in the Silvopastoral System 2 (SSP2), without shading, but with a lake for swimming. Physiological status of animals bred in the two SSP's were measured (rectal temperature-RT; respiratory frequency-RF and skin temperature-ST). The Temperature and Humidity Index (THI) and Benezra's Animal Comfort Index (ACI) were calculated, in two phases of the year, and were compared by the Tukey test $(\mathrm{P}<0.05)$. THI ranged from $73.5 \pm 1.3$ to $82.2 \pm 0.8$. RT was $38.3 \pm 0.26$ to $39.3 \pm 0.38^{\circ} \mathrm{C}$, but within the normal range for buffalo. RF ranged from $32.2 \pm 9.2$ to $56.5 \pm 19.0$ mov $\mathrm{min}^{-1}$, above the levels considered normal, and ST ranged from $23.6 \pm 8.3$ and $31.7 \pm 5.4^{\circ} \mathrm{C}$. In both periods of the year and the two SSP's, ACIs were considered higher than ideal, ranging from $2.46 \pm 0.33$ to $3.31 \pm 0.62$ (SSP1) and $2.42 \pm 0.30$ to $3.45 \pm 0.66$ (SSP2).
\end{abstract}

KEYWORDS: ambience, animal production, animal welfare, farming system.

\footnotetext{
1 Universidade Federal do Pará, E-mail: juniormoraes1@gmail.com

2 Embrapa Amazônia Oriental, E-mail: argarcia@cpatu.embrapa.br

${ }^{3}$ Universidade Federal Rural da Amazônia, E-mail: nubiasaint@yahoo.com.br

${ }^{4}$ Embrapa Amazônia Oriental, E-mail: nahum@cpatu.embrapa.br

${ }^{5}$ Universidade Federal do Pará, E-mail: Iourenco@amazon.com.br

${ }^{6}$ Universidade Federal Rural da Amazônia, E-mail: araujocv@bol.com.br

${ }^{7}$ Embrapa Amazônia Oriental, E-mail: norton@cpatu.embrapa.br
} 


\section{INTRODUÇÃO}

Os sistemas silvipastoris têm sido estudados e aplicados na agropecuária tropical, visando otimizar a utilização das áreas, uma vez que permitem a adaptaçáo de várias espécies forrageiras ao cultivo em consórcio com espécies arbóreas (Soares et al., 2009). Possibilitam, por isso, combinar a produção de plantas florestais com animais e pasto, simultânea ou sequencialmente, na mesma área, visando diminuir os impactos ambientais negativos, próprios da pecuária tradicional (Franke e Furtado, 2001). Quando o sistema silvipastoril é associado ao pastejo rotacionado intensivo, obtém-se um sistema de produção alternativo, capaz de apresentar índices produtivos mais elevados e conferir, em função do sombreamento disponível nas pastagens, maior conforto aos animais (Castro et al., 2008). Esse tipo de arranjo baseia-se no uso racional dos recursos naturais e na potencialização do desenvolvimento dos animais, e eleva a produtividade (Lourenço Júnior e Garcia, 2006). Maiores rendimentos por área podem ajudar a viabilizar a pecuária, em regióes de pastagens degradadas, evitar o desmatamento de florestas densas e promover a recuperação de áreas alteradas.

Nas regiôes de clima tropical, como a Amazônia, o estresse térmico é um dos principais entraves para a criação animal (McManus et al., 1999) e compromete sua produtividade, com redução nos ganhos de peso e na produção leiteira, reprodução e capacidade de trabalho (Ablas et al., 2007). Ainda, o estresse pelo calor determina diminuição na capacidade reprodutiva de machos e fêmeas, com impactos negativos sobre a fertilidade do rebanho (Garcia, 2006). Entre os índices usados como referência na bioclimatologia animal, merecem destaque o Índice de Temperatura e Umidade (ITU) e o Índice de Conforto de Benezra (ICB). O ITU considera o ambiente térmico que circunda o animal e é calculado segundo equaçôes que têm como fatores a temperatura do ar e a umidade relativa (Baccari Júnior, 1998), enquanto o ICB foi desenvolvido para avaliar o conforto térmico de animais criados em regióes tropicais, e considera como fatores relevantes a frequência respiratória e temperatura retal dos animais (Benezra, 1954). Ambos têm sido utilizados como índices para avaliação do conforto animal (Magalhães et al., 2006; Martins Júnior et al., 2007).

O efeito do clima sobre a produção animal é relevante na região Norte do Brasil, principalmente no Estado do Pará, que concentra $38,4 \%$ do rebanho bubalino nacional (IBGE, 2007) e apresenta elevados Índices de Temperatura e Umidade (INMET, 2008). É possível estabelecer estratégias de manejo ambiental para minimizar os efeitos climáticos sobre os animais, visando aumentar seu conforto (Das et al., 1999), principalmente em regiôes tropicais. Em áreas onde as pastagens são integradas à silvicultura, a temperatura do ar sob a copa de árvores pode ser de 2 a $3{ }^{\circ} \mathrm{C}$ inferior à observada a pleno sol, em virtude da interferência positiva da folhagem na passagem da radiação solar, o que contribui para diminuir a radiação solar sobre os animais em pastejo (Pezo e Ibrahim, 1998).

Como benefícios do maior conforto animal obtido, ocorre a otimização da produtividade, com maiores produções de leite e carne. Em sistemas que aliem essas características, pode-se aumentar o peso do bezerro ao desmame, o que reduz o período de recria dos animais e antecipa a terminaçáo dos machos para abate, além de menor idade à puberdade para fêmeas e aumento de sua vida produtiva. Assim, o objetivo do trabalho foi analisar o efeito de dois diferentes sistemas silvipastoris sobre as variáveis fisiológicas de bezerros bubalinos e comparar os índices de conforto térmico conferidos aos mesmos, do nascimento ao desmame.

\section{MATERIAL E MÉTODOS}

O experimento foi realizado na Unidade de Pesquisa Animal "Senador Álvaro Adolpho", propriedade da Embrapa Amazônia Oriental, município de Belém - PA (1²5’59” S e 48²6'29” O), no tipo climático Afi (Köppen apud Adas, 1983), quente e úmido, com chuvas bem distribuídas durante o ano todo. A temperatura do ar média anual é de $26,4^{\circ} \mathrm{C}$, umidade relativa do ar média de $84 \%$ e insolaçáo anual de $2.338,3$ horas ano ${ }^{-1}$. A precipitação pluvial média anual atinge $3.001,3 \mathrm{~mm}$ (Bastos et al., 2002).

O experimento foi executado de abril de 2007 a março de 2008. A coleta de dados dividiu-se em dois períodos experimentais, em função das datas de pariçôes das matrizes, que haviam sido sincronizadas e inseminadas em tempo fixo (IATF), em dois lotes distintos. O Período 1 (P1) ocorreu entre abril e setembro de 2007, com precipitaçáo pluvial acumulada de 1.126,0 mm, utilizando-se bezerros nascidos no mês de abril/2007; e o Período 2 (P2) ocorreu de outubro de 2007 a março de 2008 , com precipitaçáo pluvial acumulada de $1.806,4 \mathrm{~mm}$, usando-se bezerros nascidos em outubro/2007.

A área experimental era composta de dois diferentes sistemas silvipastoris: Sistema Silvipastoril 1 (SSP1), com árvores de porte elevado e que forneciam área de sombreamento útil nas pastagens e Sistema Silvipastoril 2 (SSP2), com árvores de pequeno porte, com pouco sombreamento nas pastagens e um lago para banho.

O SSP1 apresentava área de 4,57 hectares, dividida em seis piquetes para pastejo rotacionado intensivo. Todos os piquetes eram formados por grama-estrela (Cynodon nlemfuensis Vanderyst var. nlemfluensis). As instalaçôes zootécnicas possuíam centro de manejo, com bebedouro e cocho coberto, para mineralização ad libitum das matrizes. Ao lado das cercas foram plantadas mudas de mogno africano (Khaya ivorensis A. Chev.) e de nim indiano (Azadirachta indica A. Juss.), 
com espaçamento de quatro metros. As árvores apresentavam altura média de 12 metros, diâmetro na altura do peito médio de 20 centímetros e copa com tamanho suficiente para o fornecimento de 18 a 21\% de sombreamento de áreas de pastagem nos piquetes, para uso irrestrito e abrigo dos animais, nos períodos mais quentes do dia.

O SSP2 era formado por área de 10,94 hectares, dividido em seis piquetes, para pastejo rotacionado intensivo, e centro de manejo, com cocho coberto para mineralização, além de lago artificial, para banho dos animais e ingestâo de água. Todos os piquetes eram formados por quicuio-da-amazônia (Brachiaria humidicola (Rendle) Schweick...). Nas cercas perimetrais e divisórias, eletrificadas, foram plantadas, em setembro 2005, mudas de acácia-mangium (Acacia mangium Willd.), as quais ainda não apresentavam altura e folhagem suficientes para o fornecimento de sombra útil aos animais nos piquetes à época do experimento ( $0 \%$ de sombreamento). O mapa georreferenciado ilustra os sistemas silvipastoris experimentais (Figura 1).

Foram utilizados 19 bezerros bubalinos, filhos de búfalas inseminadas artificialmente, em tempo fixo, com sêmen de mesmo touro, com prova positiva para ganho de peso (Promebul, 2004), de modo a produzir lote homogêneo quanto à genética paterna. Desses, onze animais nasceram no mês de abril de 2007 e foram avaliados no Período 1 do ano experimental, e os outros oito, nascidos no mês de outubro de 2007, foram analisados no Período 2 do ano experimental. Os bezerros foram avaliados do nascimento até a $26^{a}$ semana de idade, após a qual foram desmamados.
Todos os partos foram monitorados e, após o nascimento, realizados procedimentos rotineiros de cuidados com máe e filho, tais como curativos, vermifugação e identificação, com brincos plásticos numerados. As vacinaçóes de todos os animais, durante o período experimental, seguiram o protocolo estabelecido por Láu (1999).

Em cada período experimental, após os nascimentos, as matrizes e seus respectivos bezerros foram distribuídos nos dois sistemas silvipastoris, com base no histórico individual de produção leiteira em parições prévias, de modo que a produção leiteira média dos lotes fosse homogênea, durante o experimento. A produçáo leiteira das búfalas, no Período 1, foi de 9,03 $\pm 1,06 \mathrm{~kg} \mathrm{dia}^{-1}$ e, no Período 2, foi de 6,79 \pm $1,43 \mathrm{~kg} \mathrm{dia}^{-1}$.

As informaçóes sobre as variáveis ambientais foram monitoradas na Estaçáo Meteorológica da Embrapa Amazônia Oriental, localizada na área experimental. Para caracterização do clima local, durante o ano experimental, foram medidos e extraídos diariamente dados climáticos de temperatura do ar, umidade relativa do ar, precipitação pluvial e insolação ou brilho solar, e calculadas as médias mensais expressas em ${ }^{\circ} \mathrm{C}$, $\%, \mathrm{~mm} \mathrm{mês}^{-1} \mathrm{e}$ h mês ${ }^{-1}$, respectivamente. Dados instantâneos de temperatura do ar $\left({ }^{\circ} \mathrm{C}\right)$ e umidade relativa do ar $(\%)$ foram aferidos às $6 \mathrm{~h} 00,12 \mathrm{~h} 00 \mathrm{e} 18 \mathrm{~h} 00$.

$\mathrm{O}$ índice de temperatura e umidade foi calculado pela fórmula proposta por Kelly e Bond (1971): ITU = ts + 0,55 (1 - UR) (ts - 58), onde: ts é a temperatura do termômetro de bulbo seco, em graus Fahrenheit (F), e UR é a umidade
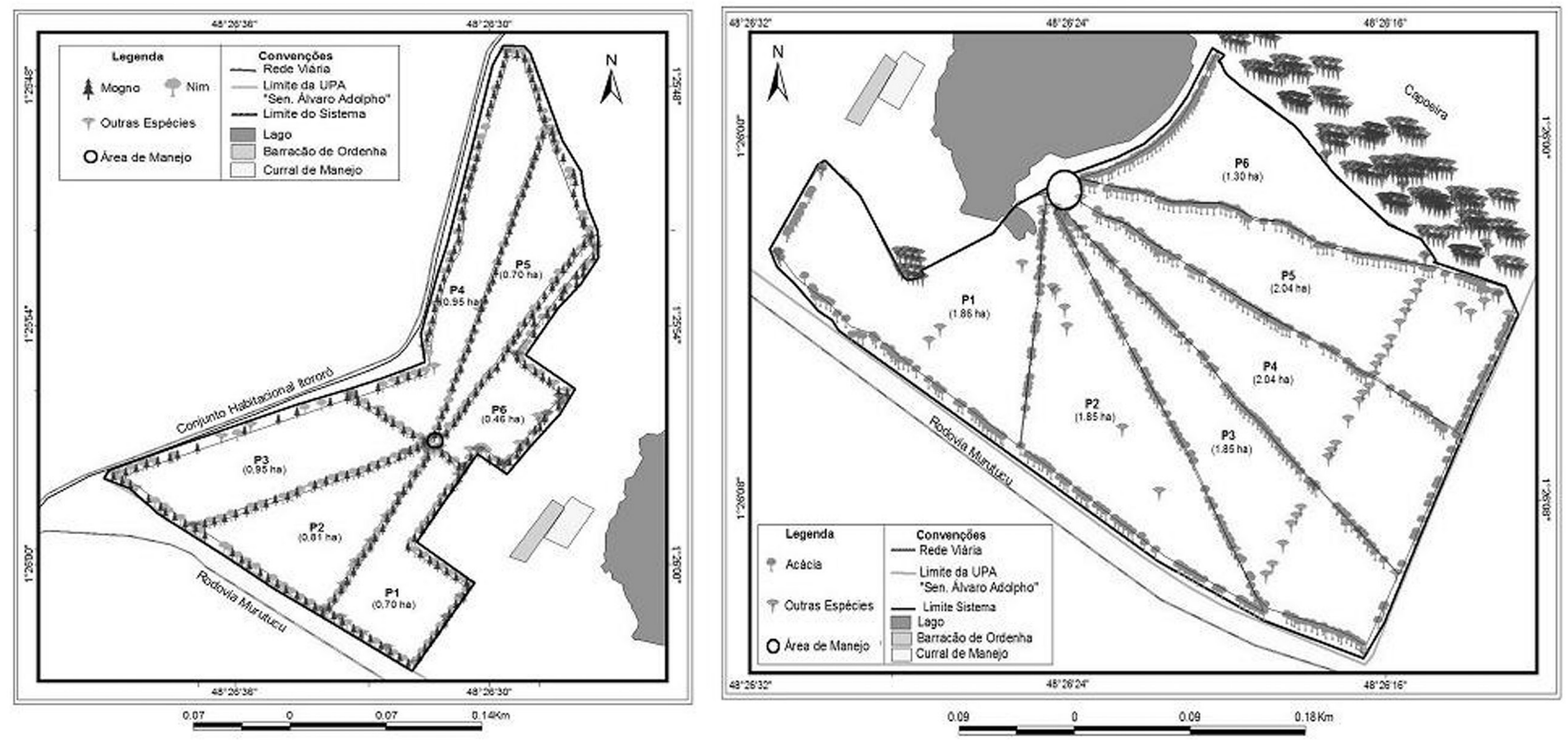

Figura 1 - Mapas do Sistema Silvipastoril 1 e do Sistema Silvipastoril 2, na Unidade de Pesquisa Animal “Senador Álvaro Adolpho", em Belém-PA. Destaque para o centro de manejo de animais, piquetes para pastejo rotacionado intensivo, distribuição das árvores ao longo das cercas limítrofes e divisórias dos sistemas. 
relativa do ar. Para transformação das temperaturas foi usada a formula ${ }^{\circ} \mathrm{C} / 5=(\mathrm{F}-32) / 9$.

As variáveis fisiológicas dos bezerros foram aferidas, individualmente, em instalação protegida contra sol e chuva, uma vez por semana, durante 26 semanas de coleta (seis meses), em cada período estudado. As mensuraçôes foram feitas, sempre às $6 \mathrm{~h} 00,12 \mathrm{~h} 00 \mathrm{e} 18 \mathrm{~h} 00$, nos mesmos dias em que foram realizadas as coletas de dados ambientais. Previamente ao dia de aferiçôes fisiológicas, os animais pernoitavam em bezerreiro coberto, de modo que as aferiçóes realizadas às $6 \mathrm{~h} 00$ fossem consideradas como estando sob efeitos mínimos dos SSP's. Para as aferiçóes às $12 \mathrm{~h} 00$ e 18h00, os animais eram gentilmente trazidos dos seus respectivos sistemas e as mensuraçóes realizadas imediatamente, após sua entrada na instalação.

Foram avaliadas a temperatura retal $\left(\mathrm{TR},{ }^{\circ} \mathrm{C}\right)$, frequência respiratória $\left(\mathrm{FR}, \mathrm{mov} \mathrm{min}^{-1}\right.$ ) e temperatura da pele (TP, $\left.{ }^{\circ} \mathrm{C}\right)$. Essas variáveis foram mensuradas da seguinte forma: a) Temperatura Retal: estabelecida com a utilização de um termômetro clínico digital, em graus Celsius $\left({ }^{\circ} \mathrm{C}\right)$ e precisão de 0,1 grau; b) Frequência Respiratória: determinada por observação da regiáo tóraco-abdominal e contagem dos movimentos respiratórios, durante um minuto; e c) Temperatura da Pele: obtida com auxílio de termômetro digital portátil de contato (fabricante: Minipa, modelo: MT-505, origem: Brasil), com escala em graus Celsius $\left({ }^{\circ} \mathrm{C}\right)$ e precisão de 0,01 grau, de leitura imediata, após toque e manutenção do sensor na região das vértebras lombares do animal.

Para a determinação do conforto dos animais foi usada a fórmula do Índice de Conforto Térmico de Benezra: ICB = $\mathrm{TR} / 38,33+\mathrm{FR} / 23$, onde TR é a temperatura retal, em graus Celsius $\left({ }^{\circ} \mathrm{C}\right)$, e FR é a frequência respiratória, mensurada em movimentos por minuto (Benezra, 1954; Magalhães et al., 2006).

Para a análise estatística foram verificadas a normalidade da distribuição dos dados, bem como a homogeneidade das variâncias, sendo realizada a transformação de dados, com finalidade de corrigir as pressuposiçóes da análise de variância, quando necessário. Para as variáveis "frequência respiratória" e "temperatura da pele" foram realizadas transformaçóes de dados na escala logarítmica, enquanto para o "índice de conforto de Benezra" foi aplicada, também, a escala logarítmica, porém adicionada a constante $100[\log (x+100)]$. $\mathrm{O}$ modelo utilizado para estudo da temperatura retal, log da frequência respiratória, log da temperatura da pele, log do índice de conforto de Benezra, temperatura do ar, umidade relativa, velocidade do vento e ITU incluiu o efeito da idade da fêmea ao parto, como covariável (linear e quadrática), período do ano experimental, SSP, aninhado em período do ano experimental, horário e interação horário com período do ano experimental, aninhado em SSP. Efeito de horários e sua interação com demais fatores foram comparados por meio de teste de Tukey, adotando-se o nível de significância de 0,05 . Para todas as análises efetuadas foi utilizado o programa Statistical Analysis System (SAS, 2002).

\section{RESULTADOS E DISCUSSÃO}

Com base nos dados climáticos médios mensais durante o ano experimental não ocorreu grande variação na média mensal da temperatura do ar e da umidade relativa do ar, durante os doze meses experimentais. Em contrapartida, a média da precipitação pluvial e do brilho solar apresentaram grande variação, durante o período (Tabela 1).

Tabela 1 - Dados médios de temperatura do ar, umidade relativa do ar, precipitação pluviométrica e brilho solar durante 0 ano experimental. BelémPA, 2007/2008.

\begin{tabular}{lcccc}
\hline Mês & $\begin{array}{c}\text { Temp. do ar } \\
\left({ }^{\circ} \mathrm{C}\right)\end{array}$ & UR $(\%)$ & PP (mm mês $\left.{ }^{-1}\right)$ & Brilho Solar $\left(\mathrm{h} \mathrm{mês}{ }^{-1}\right)$ \\
\hline Abr/07 & 26,8 & 88 & 378,6 & 135,4 \\
\hline Mai/07 & 27,3 & 85 & 223,9 & 208,8 \\
\hline Jun/07 & 27,0 & 82 & 181,5 & 245,8 \\
\hline Jul/07 & 27,0 & 82 & 142,6 & 252,3 \\
\hline Ago/07 & 27,4 & 78 & 99,2 & 253,9 \\
\hline Set/07 & 27,3 & 78 & 100,2 & 241,9 \\
\hline Out/07 & 27,4 & 81 & 136,8 & 221,5 \\
\hline Nov/07 & 27,1 & 80 & 88,5 & 208,7 \\
\hline Dez/07 & 26,7 & 87 & 399,8 & 162,0 \\
\hline Jan/08 & 26,1 & 91 & 445,3 & 107,5 \\
Fev/08 & 26,3 & 85 & 358,0 & 111,4 \\
Mar/08 & 26,4 & 84 & 378,0 & 108,6 \\
Média & 26,9 & 83,4 & 244,4 & 188,2 \\
\hline
\end{tabular}

Contudo, nas observaçôes realizadas às $6 \mathrm{~h} 00,12 \mathrm{~h} 00 \mathrm{e}$ $18 \mathrm{~h} 00$, constatou-se que a temperatura média do ar, nos dois períodos do ano experimental, foi menor às 6 horas, mais elevada às 12 horas e intermediária às 18 horas (Tabela 2), com variação de $21,5^{\circ} \mathrm{C}$ às 6 horas, no Período 2 , até o ápice de $33,5^{\circ} \mathrm{C}$, às 12 horas, no Período 1 . Já a umidade relativa do ar se apresentou bastante alta às 6 horas, com os menores valores às 12 horas e intermediária às 18 horas.

Esses dados climáticos são importantes, principalmente quando os valores atingem seus extremos, o que, no caso da temperatura do ar, ocorreu entre as 12 e 18 horas, com valores de 33,0 a $33,5^{\circ} \mathrm{C}$ no Período 1 e de 29,2 a $32,0^{\circ} \mathrm{C}$ no Período 2. Temperatura do ar elevada, principalmente quando associada a altas umidades do ar, interfere no conforto térmico e nas funçóes fisiológicas dos animais, podendo influenciar, negativamente, na produtividade animal e na velocidade das reações orgânicas. Além disso, causam respostas primárias de estresse, aumentam a temperatura corporal, a frequência respiratória e promovem a sudoração (Magalhães et al., 2006; Dantas et al., 2008). 
Tabela 2 - Temperatura e umidade relativa do ar durante período experimental. Belém-PA, 2007/2008.

\begin{tabular}{|c|c|c|c|c|c|c|c|c|c|c|}
\hline \multirow{2}{*}{ Variável } & \multirow{2}{*}{ Período* } & \multicolumn{3}{|c|}{$6 \mathrm{~h} 00$} & \multicolumn{3}{|c|}{$12 \mathrm{~h} 00$} & \multicolumn{3}{|c|}{$18 \mathrm{~h} 00$} \\
\hline & & Média & Máx & Mín & Média & Máx & Mín & Média & Máx & Mín \\
\hline \multirow{2}{*}{$\begin{array}{l}\text { Temp. do ar } \\
\left({ }^{\circ} \mathrm{C}\right)\end{array}$} & Período 1 & $23,6 \pm 0,6$ & 24,8 & 22,5 & $31,4 \pm 0,7$ & 33,0 & 29,4 & $29,0 \pm 2,1$ & 33,5 & 24,5 \\
\hline & Período 2 & $23,2 \pm 0,7$ & 24,2 & 21,5 & $30,3 \pm 1,3$ & 32,0 & 28,0 & $26,6 \pm 1,5$ & 29,2 & 24,0 \\
\hline \multirow{2}{*}{$\begin{array}{l}\text { UR } \\
(\%)\end{array}$} & Período 1 & $99,8 \pm 0,4$ & 100 & 99 & $62,9 \pm 5,0$ & 79 & 54 & $76,5 \pm 13,6$ & 99 & 50 \\
\hline & Período 2 & $98,9 \pm 1,8$ & 100 & 95 & $66,0 \pm 8,7$ & 82 & 55 & $84,0 \pm 10,8$ & 99 & 65 \\
\hline
\end{tabular}

* Período 1: de abril/2007 a setembro/2007; Período 2: de outubro/2007 a março/2008.

Por isso, faz-se necessário o manejo no ambiente de criaçáo, por meio do fornecimento de mecanismos para diminuição da ação climática direta sobre os animais, como o uso de sistemas silvipastoris, que podem abrandar os efeitos ambientais sobre os animais, principalmente nos horários mais críticos do dia. Os bovídeos, mesmo aqueles originários de zonas tropicais, entram em sofrimento nas horas mais quentes do dia, quando não dispôem de sombra, e que a conversão alimentar melhora quando, pelo menos, $5 \%$ de sombra natural nas áreas de pastagens são ofertados aos animais (Lourenço Júnior e Garcia, 2006).

Os valores médios, máximos e mínimos do ITU acompanharam a temperatura do ar e a umidade relativa do ar (Tabela 3). Os valores oscilaram entre 73,5 (às 6 horas), no Período 2, até 82,2 (às 12 horas), no Período 1 . Nos Períodos 1 e 2 houve diferença significativa $(\mathrm{P}<0,05)$ no ITU, nos três horários analisados, com pico de 84 , às 12 horas, nos dois períodos, e mínimo de 71, às 6 horas, do Período 2 . Houve, também, diferença significativa entre os períodos do ano experimental $(\mathrm{P}<0,05)$, sendo que no Período 1 os valores do ITU foram sempre superiores, nos três horários, causado, principalmente, pelo aumento da temperatura do ar, apesar da redução da quantidade de chuvas e da umidade relativa do ar.

Às 6 horas, os valores médios do ITU foram menores $(74,2$ $\pm 1,1$ e $73,5 \pm 1,3)$, devido à diminuição da temperatura do ar, que ocorre durante a madrugada, portanto, os animais encontravam-se na condiçấo ambiental mais favorável. Às 12 horas, o ITU médio era mais elevado $(82,2 \pm 0,8$ e 81,1 $\pm 1,4$ ), causado, principalmente, pelas altas temperaturas do ar que ocorrem nesse horário. Às 18 horas, o valor médio do ITU foi intermediário, entre os horários $(80,4 \pm 1,8$ e 77,9 \pm $1,8)$, mas ainda era elevado, oriundo das altas temperaturas ocorridas ao longo do dia e pela elevação da umidade do ar, causada pelas chuvas que ocorrem, geralmente, à tarde, peculiaridade da cidade de Belém, Pará.

O ITU pode ser utilizado para avaliar a condição ambiental e alerta os produtores quanto às condiçôes climáticas desfavoráveis ou que tragam risco aos animais. Segundo Ingraham et al. (1974) e Lew et al. (2006), médias de ITU ao transporem 72 são consideradas estressantes para vacas leiteiras. Já para Hahn e Mader (1997) e Somparn et al. (2004), ao atingir valores de 75 a 78, o ITU corresponde à condiçáo de alerta e pode ocorrer reduçáo na taxa de ganho de peso em bovinos e bubalinos. Entre 79 a 83, sugere condição de perigo e há perceptível decréscimo de ganho de peso e, quando o ITU ultrapassa 84, há condição de emergência, que pode levar os animais a óbito, se não houver intervenção. Entretanto, os bezerros experimentais não apresentaram o que propóem esses autores, para níveis preocupantes de desconforto térmico, o que indica elevada adaptabilidade dos bubalinos às condiçóes climáticas amazônicas e/ou a necessidade de outra interpretação da referida escala, para regióes do tipo climático Afi, como a do local experimental.

Os valores do ITU, no período experimental, foram semelhantes aos determinados por Lourenço Júnior (1998), na ilha do Marajó, entre 75 a 83. Em contrapartida, Castro (2005) cita valores próximos ou superiores a 88 , para o

Tabela 3- Índice de Temperatura e Umidade (ITU) médio, máximo e mínimo durante 0 ano experimental. Belém-PA, 2007/2008.

\begin{tabular}{|c|c|c|c|c|c|c|c|c|c|c|}
\hline \multirow{2}{*}{ Período* } & \multicolumn{3}{|c|}{$6 \mathrm{~h} 00$} & \multicolumn{3}{|c|}{$12 \mathrm{~h} 00$} & \multicolumn{3}{|c|}{$18 \mathrm{~h} 00$} & \multirow{2}{*}{ Média } \\
\hline & Média & Máx & Mín & Média & Máx & Mín & Média & Máx & Mín & \\
\hline Período 1 & $74,2 \pm 1,1^{\mathrm{aA}}$ & 76 & 72 & $82,2 \pm 0,8^{\mathrm{bA}}$ & 84 & 81 & $80,4 \pm 1,8^{\mathrm{cA}}$ & 83 & 76 & $78,9 \pm 3,7$ \\
\hline Período 2 & $73,5 \pm 1,3^{\mathrm{aB}}$ & 76 & 71 & $81,1 \pm 1,4^{\mathrm{bB}}$ & 84 & 78 & $77,9 \pm 1,8^{\mathrm{cB}}$ & 81 & 74 & $77,5 \pm 3,5$ \\
\hline
\end{tabular}

Letras minúsculas diferentes nas linhas (horário) indicam diferença significativa entre médias $(P<0,05$, teste $F)$.

Letras maiúsculas diferentes nas colunas (periodo) indicam diferença significativa entre médias ( $P<0,05$, teste $F$ )

* Período 1: abril/2007 a setembro/2007; Período 2: outubro/2007 a março/2008.

ITU = ts + 0,55 (1 - UR) (ts - 58), onde ts é a temperatura do termômetro de bulbo seco (graus Fahrenheit) e UR é a umidade relativa do ar (\%), conforme Kelly e Bond (1971). 
município de Belém, Pará, que foram consideravelmente superiores aos encontrados no presente estudo, onde em nenhum dos períodos do ano experimental e horários analisados, os valores obtidos suplantaram esse limiar. Apenas às 6 horas, os valores de ITU observados se aproximaram de 75, considerado por Baccari Júnior et al. (1986) como confortável para bubalinos.

A TR dos bezerros, nos dois períodos experimentais, variou entre $38,3 \pm 0,26$ e $39,3 \pm 0,38{ }^{\circ} \mathrm{C}$, com diferença de $1^{\circ} \mathrm{C}$, entre os extremos (Tabela 4). Esses valores encontram-se de acordo com a referência para temperatura retal de bubalinos jovens, de $38,5^{\circ} \mathrm{C}(\mathrm{FAO}, 1991)$. Como esperado, no Período 2 do ano experimental, a TR dos animais foi menor, nos dois SSP's, e nos três horários analisados, provavelmente, devido à maior dissipaçáo de calor, favorecida pela elevada quantidade das chuvas que ocorrem nesse período, aliada à maior nebulosidade, que diminui a incidência de raios solares, diretamente sobre os animais.

Tabela 4 - Média de temperatura retal $\left(\mathrm{TR},{ }^{\circ} \mathrm{C}\right)$ de bezerros bubalinos criados em sistemas silvipastoris na Amazônia Oriental. Belém-PA, 2007/2008.

\begin{tabular}{lcccc}
\hline \multirow{2}{*}{ Horário } & \multicolumn{2}{c}{ Período 1* $^{*}$ Período 2* } \\
\cline { 2 - 5 } & SSP1 & SSP2 & SSP1 & SSP2 \\
\hline $6 \mathrm{~h} 00$ & $38,5 \pm 0,28^{\mathrm{aA}}$ & $38,5 \pm 0,29^{\mathrm{aA}}$ & $38,3 \pm 0,26^{\mathrm{bA}}$ & $38,4 \pm 0,21^{\mathrm{aA}}$ \\
$12 \mathrm{~h} 00$ & $38,9 \pm 0,39^{\mathrm{aB}}$ & $38,9 \pm 0,44^{\mathrm{aB}}$ & $38,6 \pm 0,41^{\mathrm{bB}}$ & $38,7 \pm 0,37^{\mathrm{bB}}$ \\
$18 \mathrm{~h} 00$ & $39,3 \pm 0,36^{\mathrm{aC}}$ & $39,3 \pm 0,38^{\mathrm{aC}}$ & $39,0 \pm 0,40^{\mathrm{bC}}$ & $39,0 \pm 0,37^{\mathrm{bC}}$ \\
\hline
\end{tabular}

Letras minúsculas diferentes nas linhas (período) indicam diferença significativa entre médias $(P<0,05$, teste $F)$.

Letras maiúsculas diferentes nas colunas (horário) indicam diferença significativa entre médias $(P<0,05$, teste $F)$.

* Período 1: abril/2007 a setembro/2007; Período 2: outubro/2007 a março/2008. SSP1: sistema silvipastoril 1, com sombreamento útil, de 18 a $21 \%$ nas pastagens. SSP2: sistema silvipastoril 2 , sem sombreamento útil nas pastagens, com lago para banho.

Nota-se que, conforme avançou o dia, a temperatura retal dos bezerros foi incrementada significativamente, em aproximadamente $1{ }^{\circ} \mathrm{C}$, considerando-se que a temperatura retal dos animais, ao amanhecer, estava entre 38,3 e $38,5^{\circ} \mathrm{C}$, e ao final da tarde, em $39,3{ }^{\circ} \mathrm{C}$, no Período 1 , e $39,0{ }^{\circ} \mathrm{C}$, no Período 2. Nos búfalos, a temperatura corporal aumenta com o decorrer das horas do dia, sendo menor no período na manhã e mais eleveda no período da tarde (Anderson, 1988; Das et al., 1999; Magalhães et al., 2006). No caso em estudo, as temperaturas retais podem ter continuado a se elevar até o final da tarde, em função das altas temperaturas ambientais ocorrentes na Amazônia Oriental, durante manhã e tarde. Além disso, a temperatura retal, nos bubalinos, apresenta estreita relação com a temperatura do ar, mas existe atraso de, aproximadamente, três horas de permanência dessa elevação, após declínio da temperatura do ar (FAO, 1991).

Houve diferença estatística significativa na TR, entre os dois períodos do ano experimental e entre os horários analisados $(P<0,05)$. A diferença significativa entre sistemas ocorreu no horário das 6 horas, no Período 2, o que pode ser atribuído ao acaso, uma vez que os bezerros pernoitavam juntos, nos dias antecedentes às coletas de dados. Com análise dos resultados obtidos às 12 horas $\left(38,6\right.$ a $\left.38,9^{\circ} \mathrm{C}\right)$ e às 18 horas $\left(39,0\right.$ a $\left.39,3{ }^{\circ} \mathrm{C}\right)$, independente do período do ano experimental, os bezerros possuíam temperaturas retais bastante semelhantes. Assim, os bezerros que tinham acesso ao lago, para termorregulação, nos horários mais quentes do dia, em ambos os períodos, tiveram a temperatura retal muito próxima aos que tinham disponibilidade de sombreamento, o que caracteriza a elevada eficiência da sombra fornecida pelas árvores do SSP1, na facilitaçáo da termorregulação corpórea dos animais, igualmente à proporcionada pela água para banho, disponível no SSP2.

Nos bubalinos, as interferências climáticas na temperatura retal são menores, quando comparadas aos bovinos, devido à sua grande capacidade em dissipar calor corporal, principalmente, por meio da via respiratória (Koga et al., 2004). Seu hábito de procurar água para banho e a rotina de buscar sombras, nos horários mais quentes do dia, ajudam a diminuir o estresse calórico desses animais (Lourenço Júnior, 1998), o que reforça a importância do uso de sistemas silvipastoris, em ambientes de altas temperaturas e incidência solar.

Os resultados de temperatura retal são semelhantes aos de Barbosa et al. (2007), com média de $38,13{ }^{\circ} \mathrm{C}$, embora os búfalos estivessem em confinamento e adultos. Diferentemente, Koga et al. (2004) citam 39,3 $\pm 0,37{ }^{\circ} \mathrm{C}$, para bubalinos adultos confinados. Nos dois períodos do ano experimental e nos três horários analisados, os resultados foram similares aos determinados em bubalinos por Castro (2005), de 38,7 $\pm 0,39{ }^{\circ} \mathrm{C}$, e Lourenço Júnior (1998), 38,5 ${ }^{\circ} \mathrm{C}$, o qual cita TR de $38,6^{\circ} \mathrm{C}$, às 6 horas, $38,8^{\circ} \mathrm{C}$, às 12 horas, e 39,0 ${ }^{\circ} \mathrm{C}$, às 18 horas.

A frequência respiratória (Tabela 5) variou de 32,2 $\pm 9,3$ a $56,5 \pm 19,0 \mathrm{e}$, como era previsto, foi menor às 6 horas, atingiu seu máximo às 12 horas, e declinou às 18 horas. Os extremos de temperatura do ar e de ITU, às 12 horas, influenciaram a frequência respiratória dos animais, que foi exacerbada, na tentativa de intensificar a troca de calor do animal com o meio, no período da tarde, fator, também, observado por Magalhães et a. (2006), os quais verificaram que o aumento da temperatura do ar provoca desconforto nos animais e eleva a frequência respiratória, para manter a temperatura corpórea, em níveis normais.

As médias de FR foram superiores no Período 2, às 12 horas, possivelmente pela associaçâo das altas temperaturas às elevados teores de umidade, combinação que dificulta trocas térmicas, por evaporação, o que causa desconforto térmico e aumenta a frequência respiratória, para dissipaçáo do calor 
Tabela 5 - Média de freqüência respiratória ( $\left.F R, m_{0} m^{-1}\right)$ de bezerros bubalinos criados em sistemas silvipastoris na Amazônia Oriental. BelémPA, 2007/2008.

\begin{tabular}{|c|c|c|c|c|}
\hline \multirow{2}{*}{ Horário } & \multicolumn{2}{|c|}{ Período 1* } & \multicolumn{2}{|c|}{ Período 2* } \\
\hline & SSP1 & SSP2 & SSP1 & SSP2 \\
\hline $6 \mathrm{~h} 00$ & $33,3 \pm 9,8^{a A}$ & $32,2 \pm 9,3^{\mathrm{aA}}$ & $34,8 \pm 8,9^{a A}$ & $35,5 \pm 8,4^{\mathrm{aA}}$ \\
\hline $12 \mathrm{~h} 00$ & $50,5 \pm 19,6^{\mathrm{aB}}$ & $49,1 \pm 21,8^{\mathrm{aB}}$ & $53,9 \pm 19,1^{\mathrm{bB}}$ & $56,5 \pm 19,0^{\mathrm{bB}}$ \\
\hline $18 \mathrm{~h} 00$ & $46,6 \pm 14,6^{a c}$ & $45,2 \pm 12,3^{\mathrm{abc}}$ & $41,7 \pm 13,9^{\mathrm{bc}}$ & $44,4 \pm 14,4 \mathrm{abc}$ \\
\hline
\end{tabular}

Letras minúsculas diferentes nas linhas (período) indicam diferença significativa entre médias $(P<0,05$, teste $F)$.

Letras maiúsculas diferentes nas colunas (horário) indicam diferença significativa entre médias $(P<0,05$, teste $F)$.

* Período 1: abril/2007 a setembro/2007; Período 2: outubro/2007 a março/2008. SSP1: sistema silvipastoril 1, com sombreamento útil, de 18 a $21 \%$ nas pastagens. SSP2: sistema silvipastoril 2, sem sombreamento útil nas pastagens, com lago para banho.

interno. Não houve diferença estatística significativa entre os SSP's, nos horários estudados, em ambos os períodos, com apenas diferença significativa entre os horários $(\mathrm{P}<0,05)$. $\mathrm{O}$ sombreamento fornecido pelo SSP1 influenciou, de modo similar, a frequência respiratória dos bezerros bubalinos, quando comparado ao SSP2, que disponibilizava água para banho. Com base nos resultados, comprova-se a eficiência do fornecimento de sombra na reduçáo da FR aos animais em pastejo, conforme menciona Barbosa et al. (2004), que observaram diferença na FR, no período da tarde, para bovinos, com média de 94,79 $\pm 29,86$ (ao sol) e 68,25 \pm 18,17 (à sombra).

Os valores de FR aferidos foram similares aos de Magalhães et al. (2006) para bubalinos, de 45,82 $\mathrm{mov}^{\mathrm{min}^{-1}}$, com FR de 33,31 mov $\mathrm{min}^{-1}$, de manhá, e 58,33 $\mathrm{mov} \mathrm{min}^{-1}$, à tarde, e mais elevados dos observados por Barcelos (1984), no sudeste brasileiro, que evidenciou variação da frequência respiratória de 12 a $17 \mathrm{mov} \mathrm{min}^{-1}$. Castro (2005) detectou frequência respiratória, entre 21 e $27 \mathrm{mov}^{\mathrm{min}^{-1}}$, enquanto Lourenço Júnior (1998), 18, 24 e $18 \mathrm{mov} \mathrm{min}^{-1}$, às 6 horas, 12 horas e 18 horas, respectivamente. Vale lembrar que esses autores observaram essas médias em búfalos adultos, e que os bezerros, fisiologicamente, apresentam ritmo respiratório mais acelerado. $\mathrm{O}$ valor de referência para animais adultos, em currais abertos, é de 21 a mov $\mathrm{min}^{-1}$, enquanto para búfalos jovens é de $29 \mathrm{mov}^{\mathrm{min}^{-1}}$ (FAO, 1991).

A temperatura da pele apresentou efeito do horário e do período experimental $(\mathrm{P}<0,05)$ e teve amplitude de 23,6 ${ }^{\circ} \mathrm{C}$ a $31,7^{\circ} \mathrm{C}$ (Tabela 6). No Período 1 , a TP dos bezerros foi superior à do Período 2, nos horários de 6 horas e 12 horas. Como esperado, no Período 1, devido à maior incidência da radiação solar direta nos animais, os menores valores de TP ocorreram às 6 horas $\left(25,5 \pm 8,9\right.$ e 25,4 $\left.\pm 9,1{ }^{\circ} \mathrm{C}\right)$, os intermediários às 18 horas $\left(29,2 \pm 6,9\right.$ e $\left.29,8 \pm 6,8{ }^{\circ} \mathrm{C}\right)$ e os maiores às 12 horas $\left(30,5 \pm 4,9\right.$ e $\left.30,3 \pm 5,0^{\circ} \mathrm{C}\right)$. A maior absorção de raios infravermelhos, pela pele escura dos bubalinos (FAO, 1991), pode explicar o incremento da temperatura da pele, às 12 horas.

Tabela 6 - Média de temperatura da pele $\left(\mathrm{TP},{ }^{\circ} \mathrm{C}\right)$ de bezerros bubalinos criados em sistemas silvipastoris na Amazônia Oriental. Belém-PA, 2007/2008.

\begin{tabular}{lcccc}
\hline \multirow{2}{*}{ Horário } & \multicolumn{2}{c}{ Período 1* } & \multicolumn{2}{c}{ Período 2* } \\
\cline { 2 - 5 } & SSP1 & SSP2 & SSP1 & SSP2 \\
\hline 6 h00 & $25,5 \pm 8,9^{\mathrm{aA}}$ & $25,4 \pm 9,1^{\mathrm{aA}}$ & $23,7 \pm 8,4^{\mathrm{bA}}$ & $23,6 \pm 8,3^{\mathrm{bA}}$ \\
$12 \mathrm{~h} 00$ & $30,5 \pm 4,9^{\mathrm{aB}}$ & $30,3 \pm 5,0^{\mathrm{aB}}$ & $25,3 \pm 6,7^{\mathrm{bB}}$ & $25,4 \pm 6,4^{\mathrm{bB}}$ \\
$18 \mathrm{~h} 00$ & $29,2 \pm 6,9^{\mathrm{aB}}$ & $29,8 \pm 6,8^{\mathrm{abB}}$ & $31,2 \pm 5,3^{\mathrm{bCC}}$ & $31,7 \pm 5,4^{\mathrm{cC}}$ \\
\hline
\end{tabular}

Letras minúsculas diferentes nas linhas indicam diferença significativa entre médias $(P$ $<0,05$, teste $\mathrm{F}$ ).

Letras maiúsculas diferentes nas colunas indicam diferença significativa entre médias $(P<0,05$, teste $F)$

* Período 1: abril/2007 a setembro/2007; Período 2: outubro/2007 a março/2008. SSP1: sistema silvipastoril 1, com sombreamento útil, de 18 a $21 \%$ nas pastagens. SSP2: sistema silvipastoril 2, sem sombreamento útil nas pastagens, com lago para banho.

Contudo, o mesmo não ocorreu no Período 2, cujos valores de TP foram menores, às 6 horas $(23,7 \pm 8,4$ e 23,6 $\left.\pm 8,3^{\circ} \mathrm{C}\right)$, intermediário, às 12 horas $(25,3 \pm 6,7$ e $25,4 \pm$ $\left.6,4^{\circ} \mathrm{C}\right)$ e maior, às 18 horas $\left(31,2 \pm 5,3\right.$ e $\left.31,7 \pm 5,4^{\circ} \mathrm{C}\right) . \mathrm{O}$ aumento da TP, das 12 horas para as 18 horas, foi causado, possivelmente, pela permanência dos animais expostos à radiaçáo solar, pois, em consequência do aumento de chuvas e nebulosidade, nesse período do ano, acredita-se que os animais despendam menos tempo à sombra e na água para efetuar termólise. Diferentemente, presume-se que, no Período 1, quando geralmente ocorre radiação solar mais intensa, os animais ficaram abrigados na sombra ou permaneceram no lago, para dissipação do calor corpóreo. Portanto, novos estudos poderiam incluir o comportamento dos bezerros durante o dia, nos dois períodos do ano experimental, a fim de comprovar essa suposição.

Vale ressaltar que não houve diferença estatística significativa entre os dois sistemas silvipastoris e os três horários analisados. Entretanto, no Período 2, houve diferença estatística significativa entre os três horários analisados, em cada SSP, diferentemente do Período 1, quando não houve diferença estatística entre às $12 \mathrm{~h} 00$ e $18 \mathrm{~h} 00$.

Isso pode comprovar que, tanto no Período 1, quanto no Período 2, o sombreamento foi tão eficiente quanto o acesso à água para banho, na manutenção da temperatura da pele, em animais jovens. A diferença básica, a favor do uso do sombreamento, é que os animais abrigados à sombra usufruem do efeito de quebra de luminosidade, oferecida pela copa das árvores, não acumulam tanta energia térmica e não necessitam despender excessiva energia para efetuar perda de calor corpóreo. Diferentemente, os animais com acesso à água precisam mobilizar parte de sua atividade metabólica para a perda de calor inconvenientemente acumulado, pois permanecem em áreas não sombreadas. Esse fato pode ter 
impacto positivo no desempenho dos animais mantidos em sistemas silvipastoris, com sombra suficiente para sua proteção, pois a partição de energia dos animais, nesses sistemas, pode ser direcionada para seu crescimento, ao invés da termólise.

Os valores de TP encontrados neste estudo, em todos os horários e períodos avaliados, ficaram abaixo do relatado para bovinos adultos, que não tinham acesso à sombra, com TP maior que $40{ }^{\circ} \mathrm{C}$ (Azevedo et al., 2005) e para bezerros bovinos, de 35,6 $\pm 3,2 \circ \mathrm{C}$ (Santos et al., 2005). Também, ficaram abaixo do descrito por Costa (2007), para bubalinos criados em clima seco e subúmido, no nordeste brasileiro, de $37,88^{\circ} \mathrm{C}$, no período da manhã, e $38,63^{\circ} \mathrm{C}$, à tarde. Isso demonstra que os SSP1 e SSP2 foram capazes de conferir aos bezerros bubalinos adequadas proteçóes no ambiente da Amazônia Oriental, pois com menores temperaturas da pele, aumenta-se o gradiente térmico entre o núcleo corpóreo e a superfície da pele, o que favorece a transferência passiva de calor.

As médias de ICB calculadas para animais experimentais, às 6h00, $12 \mathrm{~h} 00$ e 18h00, nos Períodos 1 e 2 do ano experimental, foram, respectivamente, para SSP1 e SSP2, de 2,90 $\pm 0,74$ e 2,80 $\pm 0,73$, no Período 1 , e 2,90 $\pm 0,72$ e $3,00 \pm 0,74$, no Período 2 (Tabela 7). Os valores extremos de ICB foram de 2,42 $\pm 0,30$ e 3,45 $\pm 0,66$, ambos aferidos nos animais do SSP2. Houve efeito significativo do horário analisado, da fase e da interação SSP com horário $(\mathrm{P}<0,05)$. Não houve diferença estatística significativa entre os sistemas silvipastoris, nos três horários analisados, tanto no Período 1, quanto no Período 2.

Tabela 7 - Índice de Conforto Animal de Benezra (ICB) de bezerros bubalinos criados em sistemas silvipastoris na Amazônia Oriental. Belém-PA, 2007/2008.

\begin{tabular}{lcccc}
\hline \multirow{2}{*}{ Horário } & \multicolumn{2}{c}{ Período 1* $^{*}$ Período 2* } \\
\cline { 2 - 5 } & SSP1 & SSP2 & SSP1 & SSP2 \\
\hline $6 h 00$ & $2,46 \pm 0,33^{\mathrm{aA}}$ & $2,42 \pm 0,30^{\mathrm{aA}}$ & $2,51 \pm 0,34^{\mathrm{aA}}$ & $2,54 \pm 0,33^{\mathrm{aA}}$ \\
$12 \mathrm{~h} 00$ & $3,22 \pm 0,55^{\mathrm{abB}}$ & $3,15 \pm 0,42^{\mathrm{aB}}$ & $3,31 \pm 0,62^{\mathrm{bcB}}$ & $3,45 \pm 0,66^{\mathrm{cB}}$ \\
$18 h 00$ & $3,05 \pm 0,40^{\mathrm{aC}}$ & $2,99 \pm 0,30^{\mathrm{abC}}$ & $2,83 \pm 0,46^{\mathrm{bC}}$ & $2,96 \pm 0,52^{\mathrm{abC}}$ \\
Média & $2,90 \pm 0,74$ & $2,80 \pm 0,73$ & $2,90 \pm 0,72$ & $3,00 \pm 0,74$ \\
\hline
\end{tabular}

Letras minúsculas diferentes nas linhas indicam diferença significativa entre médias $(P$ $<0,05$, teste $\mathrm{F}$ ).

Letras maiúsculas diferentes nas colunas indicam diferença significativa entre médias

$(P<0,05$, teste $F)$

* Período 1: abril/2007 a setembro/2007: Período 2: outubro/2007 a março/2008. SSP1: sistema silvipastoril 1, com sombreamento útil, de 18 a $21 \%$ nas pastagens. SSP2: sistema silvipastoril 2, sem sombreamento útil nas pastagens, com lago para banho.

Como esperado, em ambos os períodos experimentais, às $6 \mathrm{~h} 00$, foram observados menores valores de ICB, sendo os maiores detectados às $12 \mathrm{~h} 00$, quando os índices de ITU atingiram níveis máximos, o que elevou, também, a frequência respiratória dos animais. Às 18h00, os valores de ICB decresceram significativamente, quando comparados às $12 \mathrm{~h} 00$, em ambos os sistemas, independentemente do período do ano experimental. Os menores valores de ICB, ao amanhecer e ao anoitecer, podem justificar o comportamento habitual dos bubalinos de pastejar e caminhar durante o período noturno (Lourenço Júnior, 1998).

Nos dois períodos experimentais, o ICB, aferido às $6 \mathrm{~h} 00$, ficou mais próximo ao valor de 2,0, considerado ideal por Benezra (1954), possivelmente devido à baixa temperatura e alta umidade relativa do ar que ocorrem durante a madrugada e minimizam a necessidade de termólise. Nesse horário, foi observado o nível máximo do conforto animal para os bezerros bubalinos, no período experimental. No horário das $12 \mathrm{~h} 00$, os animais apresentaram os maiores valores de ICB, considerado o ápice do desconforto, com valores intermediários às $18 \mathrm{~h} 00$. Houve diferença estatística significativa $(\mathrm{P}<0,05)$ entre os ICBs mensurados às $6 \mathrm{~h} 00,12 \mathrm{~h} 00 \mathrm{e} 18 \mathrm{~h} 00$.

Nos três horários estudados, os valores do ICB dos bezerros foram similares entre o SSP1 e o SSP2. Isso demonstra que o sombreamento nas pastagens confere aos animais, em pastejo, os mesmos níveis de conforto, em comparação com os que usam a água para banho. Esse efeito benéfico do sombreamento sobre o ICB de bezerros foi verificado, também, por Castro (2005), que encontrou ICB entre 1,9 a 2,2, para bubalinos adultos, criados em sistema silvipastoril, em Belém, PA, e por Garcia et al. (2007), que não encontraram diferença estatística significativa $(\mathrm{P}<0,05)$, entre os valores de ICB de búfalas criadas em SSP $(2,02 \pm 0,33)$, de um grupo controle $(2,23 \pm$ $0,33)$, na fase de IATF, e nem na taxa de concepção.

Os valores de ICB, no presente trabalho, mesmo às $12 \mathrm{~h} 00$, considerado como o momento de menor conforto animal, não suplantaram 3,56, relatado por Magalhães et al. (1998), para bubalinos criados em Rondônia, o que comprova a eficiência do sombreamento e da água para banho, no conforto animal, nos sistemas estudados. Entretanto, os valores ficaram acima dos citados por Lourenço Júnior (1998), para bubalinos na Ilha de Marajó, cujos valores de ICB foram de 1,75, na estação chuvosa, e de 1,92, na estação seca. Lourenço Júnior et al. (2006) observaram ICB de 2,20, para bubalinos adultos, em sistema sem sombra, e de 2,10, em sistema sombreado, que comprova a eficiência da sombra na ambiência animal, em climas tropicais. Barbosa (2008) constatou média de 2,06 $\pm 0,20$, para o índice de conforto animal de búfalas adultas, criadas em sistema de integraçáo várzea-terra firme, em BelémPará, entre os meses de abril e agosto.

Com base nos resultados da presente pesquisa, verificou-se que a sombra fornecida pelas árvores do SSP1 proporcionou os mesmos níveis de conforto animal, quando comparados ao SSP2, que disponibilizava água para banho. Assim, o sombreamento se mostrou excelente mecanismo para manejo do ambiente, que pode ser usado no combate ao estresse térmico, uma vez que estabelece ambiente mais propício para a criação dos bezerros. Anil e Thomas (1996) afirmam que água ou lama, para imersão ou banho, aspersão de água 
ou algum outro meio, que forneça ao búfalo resfriamento, por evaporaçáo, auxiliam a termólise e manutenção da homeotermia.

Os índices determinados no período experimental ficaram acima do valor de 2,0, nível de maior ambiência dos animais criados nos trópicos (Benezra, 1954). Contudo, os bezerros não apresentaram, em média, durante todo período experimental, características físicas e comportamentais compatíveis a estresse animal. Portanto, a faixa de conforto animal para bezerros bubalinos, criados em sistemas silvipastoris, com acesso à sombra ou à água para banho, é diferente e mais elevada do proposto inicialmente para bovídeos adultos. Tal diferença deve-se, principalmente, pelo metabolismo mais acelerado dos bezerros, o que ocasiona maiores valores para variáveis fisiológicas, como frequência respiratória, frequência cardíaca e temperatura retal (FAO, 1991), com impacto nos índices que foram propostos, inicialmente, para animais adultos. Outra situação é a alta adaptabilidade dos búfalos às adversidades climáticas da Amazônia (Lourenço Júnior, 1998; Magalhães et al., 2006). Assim, é interessante recomendar estudos para definiçáo de nova faixa de valores de ICB, que aponte com maior precisão o real nível de conforto de bezerros bubalinos, criados e mantidos em sistemas de produção instalados nas regióes tropicais.

\section{CONCLUSÕES}

Apesar dos elevados Índices de Temperatura e Umidade (ITU), em ambos os períodos experimentais, os bezerros não apresentaram características que pudessem identificar estresse, o que demonstra a elevada adaptabilidade dos bubalinos às condiçóes climáticas amazônicas e/ou a necessidade de outra interpretação da escala de ITU, para bubalinos criados na Amazônia Oriental.

A frequência respiratória foi elevada nos períodos mais críticos do dia, por ser o principal meio de perda de calor corpóreo dos bubalinos. A temperatura retal esteve dentro dos padrốes normais para esses animais, e a temperatura da pele ficou abaixo do considerado normal. Isso indica que o fornecimento de sombra pelos sistemas silvipastoris é táo eficiente quanto o acesso à água para banho, na manutenção da homeotermia, além de náo impactar os ecossistemas aquáticos amazônicos.

Os índices médios de conforto animal de Benezra foram semelhantes no SSP1 e SSP2, em ambos os períodos estudados, ficando acima da faixa ideal proposta para animais de produção nos trópicos. Como bezerros bubalinos têm seu mecanismo fisiológico mais acelerado que os animais adultos, é válido considerar a possibilidade do estabelecimento de nova faixa de valores para búfalos jovens.

\section{AGRADECIMENTOS}

Ao Banco da Amazônia, à Embrapa Amazônia Oriental e à Embrapa Rondônia pelo financiamento e suporte para execuçáo do trabalho (Projeto Basa Pecuária-02.05.0.019.00.04 e 04.06.06.12.00.05). À Dra. Terezinha Bastos e à Dra. Nilza Pacheco (Laboratório de Climatologia da Embrapa Amazônia Oriental) pela concessão dos dados climatológicos. Ao Dr. Orlando Watrin (Laboratório de Sensoriamento Remoto da Embrapa Amazônia Oriental) pela elaboração dos mapas.

\section{BIBLIOGRAFIA CITADA}

Ablas, D. S.; Titto, E. A. L.; Pereira, A. M. F.; Titto, C. G.; Leme, T. M. C. 2007. Behaviour of grazing water buffaloes depending on the availability of shade and water for imersion. Ciência Animal Brasileira, 8(2):167-175 (in Portuguese, with abstract in English).

Adas, M. 1983. The climate of Brazil. geographic overview: physical, human and economic aspects. Moderna, São Paulo, SP, Brasil. p. 84-89 (in Portuguese).

Anderson, B. E. Temperature regulation and environmental physiology. In: Dukes, H. H.; Swenson, M. J. 1988. Physiology of domestic animals. Guanabara Koogan, Rio de Janeiro, RJ, Brasil. p. 623-629 (in Portuguese).

Anil, K. S.; Thomas, C. K. 1996. Comparative draught performance of cattle and buffaloes. Physiological reactions. Indian Journal Animal Science, 66(4):398-401.

Azevedo, M.; Pires, M. F. Á.; Saturnino, H. M.; Lana, Â. M. Q.; Sampaio, I. B. M.; Monteiro, J. B. N.; Morato, L. E. 2005. Estimation of upper critical levels of the temperature-humidity index for $1 / 2,3 / 4$ e $7 / 8$ lactating Holstein-Zebu dairy cows. Revista Brasileira de Zootecnia, 34(6):2000-2008 (in Portuguese, with abstract in English).

Baccari Júnior, F.; Polastre, R.; Fré, C. A.; Assis, P. S. 1986. A new index of heat tolerance for buffalo. Correlation with weight gain. In: Reunião Anual da Sociedade Brasileira de Zootecnia, 23, Campo Grande, MS. 274pp (in Portuguese, with abstract in English).

Baccari Júnior, F. 1998. Adaptation of management systems in the production of milk in hot weather. In: I Simpósio Brasileiro de Ambiência na Produção de Leite. Piracicaba, SP: FEALQ. p. 24-67 (in Portuguese).

Barbosa, D. L. M. 2008. Effect of heat stress on embryonary and fetal mortality in inseminated buffaloes (Bubalus bubalis) at Eastern Amazon. Monografia de Conclusão de Curso, Universidade Federal Rural da Amazônia, Belém, 55pp (in Portuguese, with abstract in English).

Barbosa, O. R.; Boza, P. R.; Santos, G. T.; Sakagushi, E. S.; Ribas, N. P. 2004. Effects of shade and water spray on physiological and production responses of dairy cows in tropical climate. Acta Scientiarum. Animal Sciences, 26(1):115-122 (in Portuguese, with abstract in English).

Barbosa, O. R.; Oliveira, R. A.; Sirena, R. M.; Quenehenn, I. M.; Tesolin, L. C.; Caniato, R. 2007. Comparing the responses termoregulations buffalo and cattle in confinement: rectal 
temperature and respiratory rate. In: Anais da 44a Reuniáo Anual da Sociedade Brasileira de Zootecnia. Jaboticabal, SP, 3pp (in Portuguese, with abstract in English).

Barcelos, A. F. 1984. Physiological responses of water buffalo, zebu, taurine and its crossbreeds under the effect of climate and diet. Dissertação de Mestrado, Universidade Federal de Viçosa, Viçosa, 77pp (in Portuguese, with abstract in English).

Bastos, T. X.; Pacheco, N. A.; Nechet, D.; Sá, T. D. A. 2002. Climatic aspects of Belém in the last hundred years. Embrapa Amazônia Oriental, Belém, Pará. Documentos 128. 31pp (in Portuguese).

Benezra, M. V. 1954. A new index measuring the adaptability of cattle to tropical conditions. Journal Animal Science, 13(4): 1015.

Castro, A. C. 2005. Evaluation of silvopastoral systems for productive performance of buffaloes handled under climatic conditions of Belém, Pará. Dissertação de Mestrado, Universidade Federal do Pará, Belém, Pará. 91pp (in Portuguese, with abstract in English).

Castro, A. C.; Lourenço Júnior, J. B.; Santos, N. F. A.; Monteiro, E. M. M.; Aviz, M. A. B.; Garcia, A. R. 2008. Silvopastoral system in the Amazon region: tool to increase the productive performance of buffaloes. Ciência Rural 38(8): 2395-2402 (in Portuguese, with abstract in English).

Costa, L. A. B. 2007. Thermal comfort indexes and adaptability of female buffalo grazing in the wild of Pernambuco. Dissertação de Mestrado. Universidade Federal Rural de Pernambuco, Recife, PE. 52 pp (in Portuguese, with abstract in English).

Dantas, J. A. S.; Lourenço Júnior, J. B.; Monteiro, E. M. M.; Santos, N. F. A.; Aviz, M. A. B.; Costa, D. A. 2008. Climatic variable vs. conception of buffalos in the Amazon. Archivos de Zootecnia. 57(219): 349-351 (in Portuguese, with abstract in English).

Das, S. K.; Upadhyay, R. C.; Madan, M. L. 1999. Heat stress in Murrah buffalo calves. Livestock Production Science. 61: 71-78.

FAO. 1991. The buffalo. Ministério da Agricultura. São Paulo Associação Brasileira de Criadores de Búfalos, Brasília, DF, Brasil. 320 pp (in Portuguese).

Franke, I. L.; Furtado, S. C. 2001. Silvopastoral systems: fundamentals and applicability. Embrapa Acre, Rio Branco, Acre. Documentos 74. $51 \mathrm{pp}$ (in Portuguese).

Garcia, A. R. 2006. Influence of environmental factors on reproductive characteristics of the river buffalo (Bubalus bubalis). Revista de Ciências Agrárias, 45:1-15, Supl. (in Portuguese).

Garcia, A. R.; Matos, L. B.; Nahúm, B. S.; Lourenço Júnior, J. B.; Gonçalves, K. S.; Myiasaki, M. Y. A. 2007. Importance of silvopastoral systems on thermal comfort of buffaloes undergoing protocols for fixed timed artificial insemination. In: 59a Reunião Anual da SBPC. 2pp (in Portuguese).

Hahn G. L.; Mader, T. L. 1997. Heat waves in relation to thermoregulation, feeding behavior and mortality of feedlot cattle. In: Proceedings of the 5th International Livestock Environment Symposium Minneapolis. St Joseph, Mich. ASAE. 563-567.

IBGE. Instituto Brasileiro de Geografia e Estatística. 2007. Database Clusters: Livestock. Effective Herd. (http://www.sidra.ibge.gov. br/bda/acervo). Acesso 27/02/2009 (in Portuguese).
Ingraham, R. H.; Gillete, D. D.; Wagner, W. C. 1974. Relationship of temperature and humidity to conception rate of Holstein cow in subtropical climate. Journal Dairy Science, 57: 476-872

INMET, Instituto Nacional de Meteorologia. 2008. Map of thermal comfort index. (http://athos.inmet.gov.br/html/agro. php?lnk=\%CDndice\%20de\%20Conforto\%20T\%E9rmico). Acesso 10/09/2008 (in Portuguese).

Kelly, C. F., Bond, T. E. 1971. Bioclimatic factors and their measurement. In: National Academy of Sciences. A guide to environmental research on animals. Washington, USA. 374pp.

Koga, A.; Sugiyama, M.; Del Barrio, A. N.; Lapitan, R. M.; Arenda, B. R.; Robles, A. Y.; Cruz, L. C.; Kanai, Y. 2004. Comparison of the thermoregulatory response of buffaloes and tropical cattle, using fluctuations in rectal temperature, skin temperature and haematocrit as an index. Journal Agricultural Science, 142: 351-355.

Köppen, W. apud ADAS, M. 1983, p.86.

Láu, H. D. 1999. Buffaloes diseases in Brazil: epidemiology, diagnosis and control. Embrapa, Brasília, Distrito Federal. 202 pp (in Portuguese).

Lew, B. J.; Meidan, R.; Wolfenson, D. 2006. Hormone concentration and follicular development in dairy cows under seasonal and acute hyperthermia. Arquivo Brasileiro de Medicina Veterinária e Zootecnia, 58(5): 816-822 (in Portuguese, with abstract in English).

Lourenço Júnior, J.B. 1998. Production, physiology and behavior of zebu cattle or buffaloes and physical environmental factors in pasture on the island of Marajó. Tese de Doutorado. Universidade Federal do Pará, Belém, Pará. 159 pp (in Portuguese, with abstract in English).

Lourenço Júnior, J. B.; Garcia, A. R. 2006. Animal production in Amazon: updates and perspectives. In: Simpósios da $43^{\text {a }}$ Reunião Anual da Sociedade Brasileira de Zootecnia. João Pessoa, PB (in Portuguese, with abstract in English).

Lourenço Júnior, J. B.; Costa, N. A.; Garcia, A. R.; Nahúm, B. S.; Araújo, C. V; Dutra, S.; Matos, J. C. S.; Matos, L. B. 2006. Silvopastoral systems and intensive rotational grazing on buffaloes milk production in small farms in the eastern Amazon. In: $4^{\circ}$ Congreso Latinoamericano de Agroforesteria para la Producción Pecuaria Sostenible. Matanzas, Cuba : Universidad de Matanzas. 24-27 (in Portuguese).

Magalhães, J. A.; Takigawa, R. M.; Tavares; A. C.; Townsend, C. R.; Costa, N. L.; Pereira, R. G. A. 1998. Cattle tolerance to temperature and humidity at humid tropics. Embrapa Rondônia, Porto Velho, Rondônia. Documentos 147. 4pp (in Portuguese).

Magalhães, J.; Townsend, C. R.; Costa, N. L; Pereira, R. G. A. 2006. Determination of cattle and buffaloes heat tolerance on the humid tropics. In: $4^{\circ}$ Congresso Brasileiro de Biometeorologia. Ribeirão Preto, SP. 6 pp (in Portuguese, with abstract in English).

Martins Júnior, L. M.; Costa, A. P. R.; Azevêdo, D. M. M. R.; Turco, S. H. N.; Campelo, J. E.G. ; Muratori, M. C. S. 2007. Boer and anglo-nubiana goats adaptability in the Brazil middle-north climatic conditions. Archivos de Zootecnia, 56 (214): 103-113 (in Portuguese, with abstract in English). 
McManus, C.; Brenner, H.; Saueressig, M. 1999. Heat tolerance of cows in dual-purpose cattle system Embrapa Cerrados. In: 36a Reuniáo Anual da Sociedade Brasileira de Zootecnia. Porto Alegre, RS. 35 pp (in Portuguese, with abstract in English).

Pezo, D.; Ibrahim, M. 1998. Sistemas silvipastoriles. CATIE, Proyecto Agroflorestal CATIE/GTZ, Turriba, Costa Rica. Materialies de Enseñanza/CATIE, 40. 12 pp (in Spanish).

Promebul. 2004. Promebul: summary of buffalo bulls. UNESP, Botucatu, SP, 37 pp (in Portuguese).

Santos, S. A.; McManus, C.; Souza, G. S; Soriano, B. M. A., Silva, R. A. M. S.; Comastri Filho, J. A.; Abreu, U. G. P.; Garcia, J. B. 2005. Variation in rectal and skin temperature of pantaneira and nelore cows and calves in the Pantanal. Archivos de Zootecnia, 54: 237-244 (in Portuguese, with abstract in English).
SAS. Statistical Analyses System. 2002/2003 User's guide: Stat, Version 9.1.3. SAS Institute, Cary.

Soares, A. B.; Sartor, L. R.; Adami, P. F.; Varella, A. C.; Fonseca, L.; Mezzalira, J. C. 2009. Influence of luminosity on the behavior of eleven perennial summer forage species. Revista Brasileira de Zootecnia, 38(3): 443-451 (in Portuguese, with abstract in English).

Somparn, P.; Gibb, M. J.; Markvichitr, K.; Chaiyabutr, N.; Thummabood, S.; Vajrabukka, C. 2004. Analisys of climatic risk for cattle and buffalo production in northeast Thailand. International Journal Biometeorology, 49: 59-64.

Recebido em 25/07/2009

Aceito em 04/03/2010 
